\title{
The Running Tongue: Collaboration, Choice, and Community
}

Siobhan Davies and David Hinton, in conversation with Simon Ellis

Thursday 6th February 2015

The Running Tongue is a new film installation work by Siobhan Davies and David Hinton. It features a woman-Helka Kaski-running continuously and then appearing or jumpcutting into different and very brief scenes_or "visions" - that have been developed with Davies and Hinton by more than 20 independent dance artists in the UK. Such a large-scale collaboration resulted in a complex series of negotiations between the artists. In this interview, Davies and Hinton discuss The Running Tongue with IJSD coeditor-and one of the artists involved in the project-Simon Ellis.

Simon Ellis-Can you talk about how The Running Tongue started?

Siobhan Davies-David and I have known each other for thirty years and have always wanted to work together. We made All This Can Happen in 2012. And after that we both wanted to work together again and an opportunity to make this second piece arrived. All This Can Happen was made by a very few people and made in this same meeting room. ${ }^{2}$ It was an intense experience, we made the work using only found footage of film and photographs many from the late nineteenth to early twentieth century. This meant an enormous amount of research-which was an unknown excitement for me-to explore the past in images. Later we worked on the careful editing and juxtaposition of all the materials. We built up such a thickness of concentration in this room, it was a hermetic experience and, while I always thought of my contribution as a choreographic one, I had not worked with any dance artists for those nine months. I had missed those exchanges with dance artists so when we began to think of this new project we both wanted to work with more people, to have more traffic in this room.

SE-So you're saying that one of the starting points for The Running Tongue was that if only three of you were in this room for All This Can Happen, then how do you somehow crack it open a little bit or provide access to other people?

SD-Yes and be in conversation. Little did we know how much conversation it was going to be! We were intrigued to ask movement based artists to use their own practice and with that make a still screen image.

The International Journal of Screendance 5 (2015). 
When I helped to make All This Can Happen, I had never made a film. I had to rely on my choreographic learning to be of any use at all.

David and I wanted to work with dance artists who could apply their bodily, conceptual and choreographic learning, and their use of imagery to this different medium. It was a way for me to continue and share the experience I had had when working on the first film.

David Hinton-l'd like to pick up on something to do with our relationship, which also relates to The Running Tongue, I think. The way I met Sue was that I made a South Bank Show about her. It was in 1983 and I made a documentary following her through the process of making a piece. It was an important moment for me, as it was the first thing I had ever done that was in any way related to dance. One of the reasons I wanted to do it was as an education, because I had got a sense that contemporary dance was interesting but I knew nothing about it. Part of the beauty of making documentary films is that it is a way of educating yourself. That's always been part of my attitude to film making-it's a way of learning-and this is again the case with The Running Tongue. Through talking to 20-25 different dance artists I am learning a huge amount. It may be a sort of bonus aspect of the job, but it matters a lot to me to be learning through doing these things.

SD-That matters to me a lot as well.

$\mathrm{DH}$-In a way, All This Can Happen was about collaborating with the dead-everybody in the film is dead, Robert Walser who wrote the text is dead. For me, it was fantastic to work that way. There's this fundamental poetry about film, which is that it can bring to life long gone moments in time. A moment in 1890 can suddenly come alive again on screen and I always find that incredibly moving. But a huge part of the impulse for The Running Tongue was about going the other way-let's communicate with life around us, with people who are living now, and let's think about what's going on in the world right now.

Initially The Running Tongue was going to be a much more humble piece than it turned out to be. A large arts centre in Australia called Carriageworks saw All This Can Happen and that prompted them to commission Sue and me to make something as part of a new exhibition. The commission they were offering was quite modest, but then Siobhan Davies Dance as an organisation came in and said we will make this into a bigger production-so that's my good fortune. 

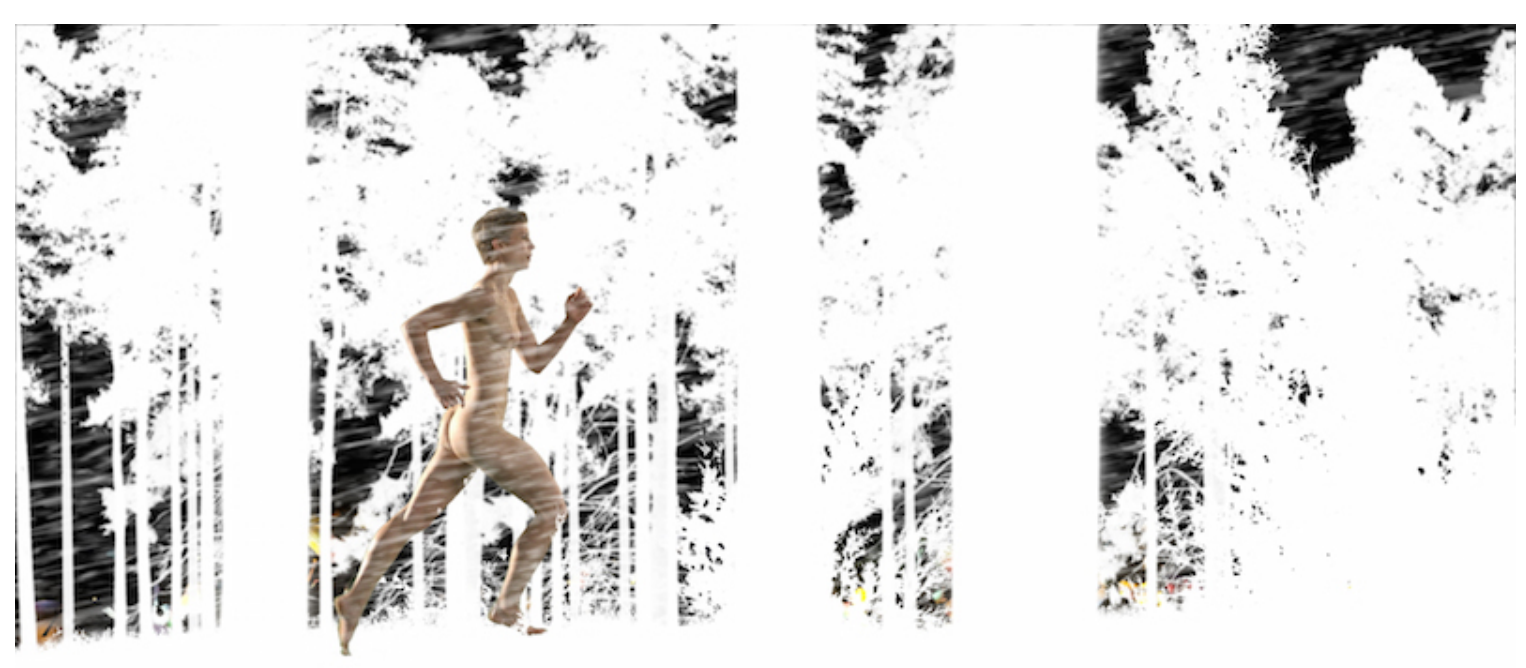

The Running Tongue, image of Helka Kaski, courtesy of Siobhan Davies Dance

SE-Could you say a bit more about these 20-25 people and how they fit in with The Running Tongue and how they fit with you?

SD-In All This Can Happen we were very drawn to the idea of isolating one frame and that a lot of information can happen within one frame.

In The Running Tongue we continued this sense of isolating frames. We wanted to give each artist a single frame and for them to fill that frame with an event, create a scene following rules or requests which David and I had constructed in order to give some coherence to the whole work. We called the frame each of the artists were going to make a "vision". We needed to devise a system in which the rules helped each artist to go through the eye of the needle in terms of rigor but also give them the freedom to explore what their practice could bring to a particular moment in time.

SE-Just to be clear when you say frame, you mean the spatial aspect. It is not a single moment in time, but it is a spatial frame played out over-or expanded to-ten seconds.

$\mathrm{DH}-$ This work is very definitely related to All This Can Happen because it continues our interest in movement that is broken down into still images. It all goes back to the origins of cinema and the earliest investigations into how movement might be rendered in photographic images. When we set to work on All This Can Happen our biggest inspiration was Étienne-Jules Marey. Together with Eadweard Muybridge, he was the great pioneering figure in terms of photographing movement and then playing the frames back in a way that gives an illusion that the movement is happening right in 
front of you. We are very interested in the fact that all movement in the form of images is an illusion, and that what we are actually seeing is a sequence of still frames. We got very interested in these Marey films that are very brief. A long Marey film might be 48 frames long, which is 3-4 seconds. When you get into that way of thinking, 10 seconds becomes a pretty epic length. It is 250 frames, and if you think that every frame is, in itself, individually interesting, then two hundred and fifty is a hell of a lot to play with.

So, with The Running Tongue, our original conception was that we would start with a burst of action that lasted ten seconds. The 100-yard sprint presented itself as exactly the right kind of thing. ${ }^{3}$ You know, Usain Bolt running for only ten seconds is also an epic thing. Say you take something like that, think of it as 250 frames and give each one of those frames to an artist to add their own information to that frame... That was the original plan, to collaborate with 250 dance artists! Then reality started closing in on us and we ended up with just over 20 artists, but the original impulse is still there-this whole idea of each individual frame being interesting and giving different artists individual frames to work with.

SD-But also thinking of it as a miniature. A single frame as a miniature, a compact place for an event to happen in amongst a stream of action. A moment or moments not easily seen by the human eye. What captured me was the level of detail which might be glimpsed by filling one arrested frame of a film before streaming back to normal frame rate.

SE-As these different "visions" have developed and evolved, how have you developed a sense of wholeness of the work?

$\mathrm{DH}$-From my point of view, the coherence of the work should derive from the proverbs: the fact that we are asking every dance artist to use their own sensibility but we are also asking them all to work from proverbs collected in a book by Mineke Schipper called Never Marry A Woman With Big Feet. ${ }^{4}$

SE-So each vision is based on a proverb from Schipper's collection, and all the proverbs are about women in some way?

$\mathrm{DH}-$ Yes. The original conception was that in these 250 frames you could create a kind of biography for the woman that you were seeing in the frames. So you take a woman, you watch her running 250 frames and you then offer each individual frame to an individual artist and each artist is providing part of her biography. Over the 250 frames you could, in fact, have a narrative that tells the whole story of her life. So you've got 10 seconds of a life and, at the same time, you've got a whole life. But actually the logistics of making the whole of that idea work have proved too demanding. 


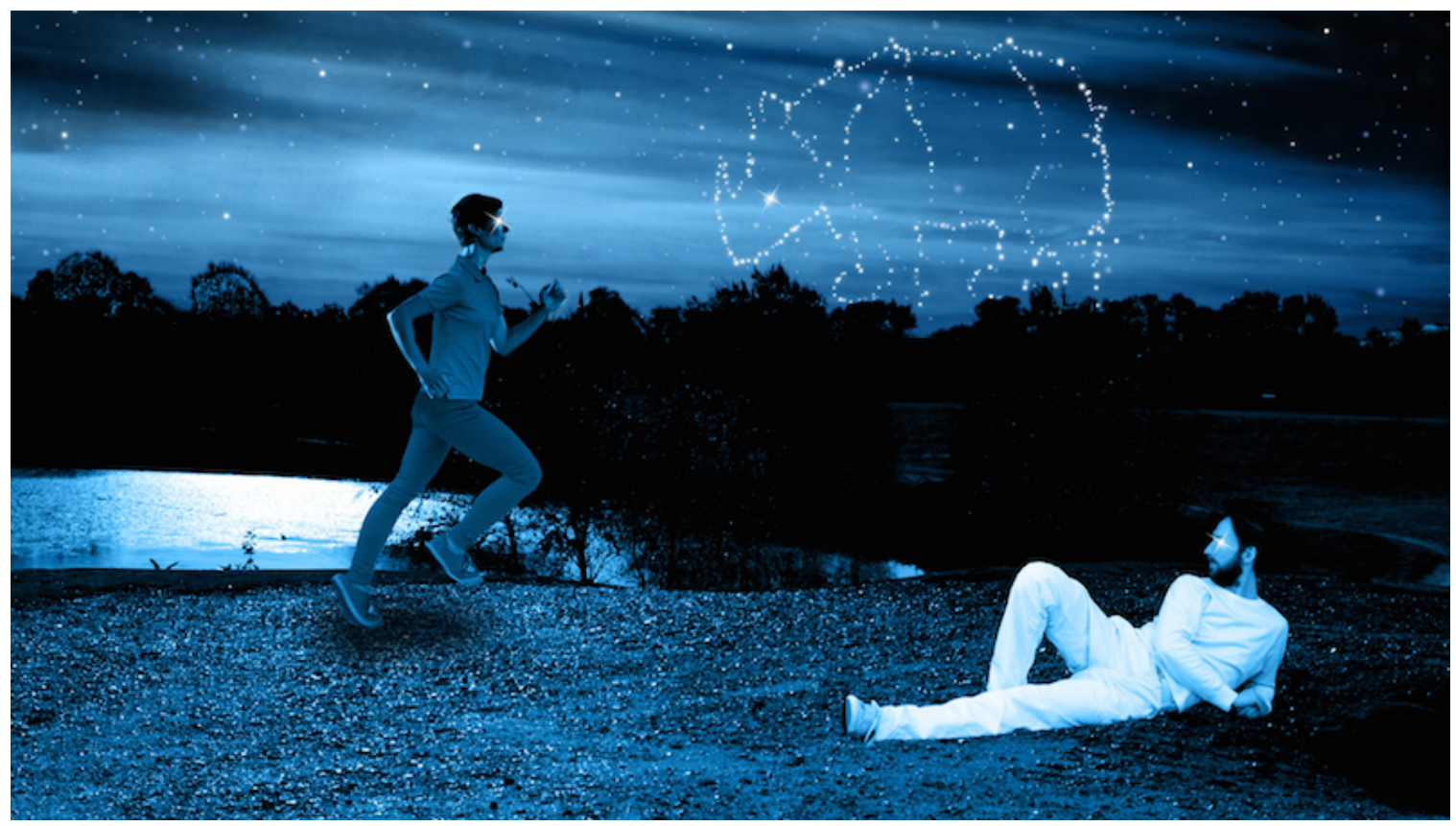

The Running Tongue, vision by Matthias Sperling

SD-Working with making a whole life would have taken freedom of choice away from the dance artists. We could have been more prescriptive with the artists by, for example, choosing a proverb for each one, and then a subject: childhood, young love, spinsterhood, witchery, etc. We didn't do that and so the choice for them as artists led us to think of a less linear strategy. Although we did provide a quite strict structure, we were always thinking about how much freedom we could give people within that structure and where that was possible and where we thought, for the sake of the whole film installation, that was not possible.

$\mathrm{DH}-$ This is the nub now. The nub of the whole collaborative enterprise is: at what point do we dictate to people and at what point do we allow freedom? It's a never-ending negotiation.

SD-It is something we think about all day. It's not something that we just invented in the beginning.

$\mathrm{DH}-$ And it comes down to every detail in every vision; you know, do we want the sky a very bright blue or a duller blue? Should we decide or should we let the dance artists decide? We worry at every level of the process about which decisions are ours and which decisions are theirs.

SD-I occasionally thought of the image of a microscope, of having microscopic eyes.

With a naked eye we see what we can but with the single frame we can go into the detail of how each vision has been constructed using collage. Every decision led to another decision. When we first introduced the structure and methods to the dance 
artists, we thought initially that it was fairly simple, but the further we went into the work more decisions were necessary-infinite if we weren't careful-as all of these decisions began to shift and push at our initial plan. We needed to think how to maintain our core structure as well as include what the artists were introducing to us.

We had not realized how many small but important decisions were a necessary part of vision-making. So many original ideas for the visions were being challenged and stretched, and we were trying to expand with it and maintain the initial values. Where we thought there might be a handful of decisions we seemed to discover hundreds. We were trying to negotiate not only the thing we thought we were making but what it was becoming.

I would like to say how much I have enjoyed every relationship that I have had with each of the artists. Each one brought us different insights into how work can be imagined. I can also say that we have tested each other in terms of how much we've asked each other to do.

SE-So how have you gone about negotiating that line between making a decision or leaving it to the artist? Where are the lines between agency and community?

$\mathrm{DH}$-The fascinating thing about this project is that it is not only about decisionmaking. With every artist you have to negotiate cultural difference in the sense that each individual has a whole culture of their own regarding their work. They have a whole set of attitudes about what they're going to think about and what they're not going to think about, what's important to them and what's not important to them. And then there are differences between Sue and me too! Obviously, we have our own different preoccupations.

SD-And then there's the animators Magali Charrier, Noriko Okaku, Tony Comley, and Rachel Davies, and the sound artists Chu Li Shewring, Raoul Brand and Zhe Wu.

$\mathrm{DH}-$ So every vision is a massive negotiation.

SD-There are moments in which communication was very clear and there are always moments where either an artist or myself have understood too late and realised that each of us has such different ways of hearing and receiving information. Someone has left the room or the phone is put down or an email read and I have thought, "Oh damn we are not quite connecting here."

We have needed to be good listeners. Each artist contributes with a different emphasis, a different attention, which we need to be on the look out for. Also negotiating even just how much time the work is taking. Each of these independent artists has very different timetables. We try to appreciate when, for instance, a term begins for those that teach, or when someone is preparing for a performance. We want to be sensitive to each artist but I also know we have been demanding. 
$\mathrm{DH}-$ This is important because with everybody there's a massive negotiation about how much energy they're going to put into the job.

SE-The Running Tongue: it's not a film installation, it's a way of life.

$\mathrm{DH}-$ Well, that's what is so interesting because for Sue and me it is a way of life, but for all the dance artists it's a very small part of their professional life, which they have to fit in around much bigger commitments. So that causes a lot of stress and strain.

SE-When you speak about it so frankly, those constant negotiations sound extraordinary. It's also because there's something fascinating about the complexity of those relationships in a small group and the threads that extend out into this larger group of people. Yet one of the things I remember Efrosini Protopapa ${ }^{5}$ and I talking about was our sense of community as a group of artists in The Running Tongue ...

DH-Yes, it's non-existent.

SE-Yes, non-existent, except occasionally you'd pass someone as you were leaving this room.

SD-In a way this is a sadness to me. I knew you were going to talk in this interview about community and I thought the people involved in The Running Tongue are more like a spider's web because I think we can sense that there might have been conversations and connections but they are not collected or shared.

DH-It's a great example of how practical things always overwhelm idealistic things. For example, early in the process, Frank Bock ${ }^{6}$ suggested all kinds of interesting ideas about how the whole group might get together and do sessions together and all that sort of thing.

SD-Which we were not against!

$\mathrm{DH}-$ Which all sounded wonderful. But when the actual practical logic of the work takes over it becomes incredibly hard to make those things happen.

SD-There do seem to have been Running Tongue conversations when some of the artists have met up outside the studios and exchanged concerns, and I think become happier as they hear how other people have found it difficult, absorbing, irritating! I hope I have heard that this process has brought a fresh look at what making can be, although David and I don't hear a lot, we are stuck in this room. We have gone through a mammoth learning process that we had not imagined ahead of time. It's a lot larger ...

DH-Because, of course, it starts off in this golden glow of thinking, "Oh we're giving these artists this wonderful opportunity to make something that's really good fun. And its really interesting for them because it's so different from what they normally do." But 
then the work goes grinding on and on, and there's still more to do, and you start to suspect that people are feeling quite burdened by it. But you don't know.

SD-I'm sure that's partly to do with individual circumstances and partly to do with expectation. I think the majority of people have gone, "Hell, but OK, I've done something I would not have except in these circumstances."

It's difficult because none of the individuals have seen any of the other visions really and they haven't seen the whole. So my fear is that they will go, "I had no idea that I was contributing to this" and with that we just have to be brave and go for it.

It is also going to be a surprise for us when we see it all together. David was very interested a while ago, and I think I agree with him, that the cohesion is the proverbs. But for me, having gone through the process up to the point that we have-and I haven't seen it put together since November when there were only ten visions-I think that the emotional cohesion for the audience will be drawn from Helka Kaski ${ }^{7}$ and her experiences. She appears in over forty visions, sometimes central to the vision, sometimes passing through them. I have felt that she is one woman and many. She lives in the present and also lives in the repeated scenarios that women experience. She also challenges those scenarios. I think that my responses are plucked by her staying power.

SE-One of the experiences that I had [as an artist in The Running Tongue] was of being responsible for certain things and the recognition of being a very small part of a much bigger thing. I would send you-it didn't even involve physical contact or coming insome video or images, and they would be released to someone else. The first time I turned up and Magali Charrier had put my first vision together and all this work had been done by someone else. It was a slightly wondrous thing. As an independent artist I'm used to doing pretty much everything by myself and the idea that something would happen whilst I wasn't present or wasn't making it happen opened my eyes to a whole other way of working.

$\mathrm{DH}-$ This relates to what I was saying before about this idealistic dream. We felt we were giving everybody a fantastic opportunity because what we were saying was: "You dream something up and we will make it exist."

SE-How does that feel now?

$\mathrm{DH}-$ Well, it is fascinating how people respond, because some people will immediately get it and think, "Oh, all I have to do is imagine something, and then there's all these other people who will turn it into an image." But some of the dance artists were immediately thinking, "Oh, my God, now I've got to learn how to use Photoshop." They are so used to doing everything themselves-and so used to being practically and physically involved with everything they do-that the idea of just dreaming something up doesn't come into their realm of thinking about making work. 
SD-I think that as individual artists we learn by going through a process and one part of the process leads to the other. In this instance the dance artist might miss part of the process and have to catch up because somebody else-the visual artist using animation-was in charge of that part. So that missing link was either a joy or it was a disruption. I am hoping that in the main they didn't find this stressful and if they did then we'd go try again. But they would have to go through a period of adjustment with themselves; a negotiation to get to the next place that another artist had taken them to, another visual artist. So the process of doing wasn't always consecutive so I imagine that was challenging. Not in a negative way always but definitely a hiccough.

SE-Have you experienced a similar situation before? Have you thought, "This reminds me of this?"

$\mathrm{DH}-\mathrm{No}$ and I think the important thing about what we are doing is that it is a really experimental work. I've never ever been in circumstances like this.

SD-I have tried to include artists as co-authors in past work, in fact I have always done it on a certain level, to recognize those artists who are bringing work to the table. I am very lucky to work within that structure. It is important to me to help create situations like that. But working within this project feels very different and I think that it is because often dance is made through a range of processes, feedbacks from physically doing something, there seems to be more air between deciding, making, doing and performing. We have to use the time it takes to breathe in and out, to raise or lower an arm.

In The Running Tongue-with each vision a 10-second frame-we needed many elements to exist at once, and David and I asked that movement should be considered a luxury, so spare but precise decisions needed to be made often at the same time. Where should a figure be exactly in what pose? How does that pose and no other communicate? What relationship are they to another? In what speed do they move? How does all of this work in a collage? The language felt very precise.

We do use precision in our dance practice, but I also enjoy the spaciousness of performed movement. Precision seems hyper-condensed in the films I have been involved in; every millimeter in a frame can be thought about, as well as every millisecond. No waste!

I think that what has made it exciting as a new medium for me-and this is where I learn a lot from David-is to notice what is going on at an exact level with color, texture, movement, timing, performance, idea, concept, recognition, audience. To do this within a tiny amount of time certainly feels like a different kind of archaeological practice that we put ourselves through in order to make each vision.

SE-The distinction that you are making between the air or the spaciousness of being in the studio, do you think it is about the particularities of the sense of time and the way 
time is being organized in The Running Tongue or is it about working in front of a screen and the kind of compression that isn't necessarily particular to this type of project?

SD-I think there is something about compression but I counterpoint what I have just said with the idea that I think a dance artist who has practice behind them actually has the tools to do this work with film or photography. But there is something to do with the compression. I think dance-artists have exactitude in our durational timeline as performance makers or dancers, but in The Running Tongue we take the exactitude through a different eye of the needle in order to arrive at this still image. So one of the things which supported me-and I hoped I managed to get across to the other artistsis that if you look at painting from pre-history to now when a visual artist has chosen which part of an action to capture, what knowledge went into choosing that particular moment? Whether it's on a Greek vase, a renaissance painting or whether its Stanley Spencer or Tracey Emin. There is a long line of accrued knowledge about human expression in movement that has been stilled. So there's something about knowledge in the world that is knowing when is the right moment to capture a human gesture. Experiencing everybody else's work through doing this has made me want to look more deeply at this understanding. I feel like we have had the opportunity to look at that extraordinarily throughout this project.

DH-Film has got absolutely nothing to do with that. There's no openness at all in film. Everything is highly determined, completely specific and requires a decision. You can't leave anything unresolved. Somebody has got to make the decision: is the wine bottle going to be there, or is it not going to be there? Do we want to move it two inches to the right, or two inches to the left? Everything has to be decided and determined.

SD-To add to that, I think that so many things are decided in performance in terms of the structure that you wish to take your performance through at that moment. I think we do have an exactitude but it is tempered by the full experience of performance, and this includes everything that can happen in a performance: your relationship to the audience, the space, yourself, the material and whatever else. We both have exactitude but there is something very different, there is some other element that comes into play when you are working with the screen.

SE-It is a different set of constraints. It is curious that when you were talking about performance I was thinking about gathering and the way in which performers gather, and an audience gathers, and what you have done here is the gathering has been in series and sometimes it has been virtual where you have been contacting people and material has been uploaded. It has been absent this sense of a singular gathering; it has been multiple gatherings and it is fascinating as a way of making something.

SD-And where we have done this well enough-where we have provided the structure well enough-I feel there's a sort of equality being generated as we have tried to bring 
everything in it's different ways up and through and into the making of this film installation.

We have also been in a position of adding, with respect, to each of the individual artists' work. This is because of practical things like, for example, filming it at the right resolution or finding something that is copyright free. So there are ways in which we wanted to honor the work but also things we had to alter.

$\mathrm{DH}-\mathrm{A}$ big part of what we are trying to do is give dance artists control over the image. I have worked in dance now for a long long time and normally the way it works is that dance artists are used as choreographers and performers, but, in the end. it is someone in the film world who actually controls the image. We are really interested in investigating what happens if you hand over control to the dance artist and say, "This image belongs to you, what do you want to see in it?"

The Running Tongue will be installed at Carriageworks, Australia as part of a new major exhibition 24 Frames Per Second, 18 June - 2 August 2015, for full details visit www.siobhandavies.com

\section{Biographies}

Director David Hinton has made many television documentaries, twice winning a British Academy Award, and his dance films have won many awards, including a Prix Italia, an Emmy, and the IMZ Dance Screen Award. His subjects have included artists of all kinds, including painter Francis Bacon, film-maker Bernardo Bertolucci, writer Alan Bennett, and choreographer Karole Armitage. He has also made films about Dostoyevsky, rock and roll, visual comedy, and the Cultural Revolution in China. He is best known in the dance world for Dead Dreams of Monochrome Men and Strange Fish, his film versions of stage shows by DV8 Physical Theatre. He has also made performance films with Adventures in Motion Pictures, the Alvin Ailey American Dance Theatre and the Royal Swedish Ballet, and he has collaborated with several choreographers to create original dance works for the screen.

Siobhan Davies is a renowned British choreographer. Founding Siobhan Davies Dance in 1988, she has consistently worked closely with collaborating dance artists to ensure that their own artistic enquiry is part of the creative process. By 2002 Davies moved away from the traditional theatre circuit and started making work for gallery spaces and alternative locations, including an aircraft hangar and art galleries.

In 2006, the RIBA award-winning Siobhan Davies Studios opened in London, UK, realising Davies' long-standing goal of establishing a permanent base for her 
organisation and for independent dance artists. Davies works alongside independent dance artists to create new work and applies choreography across a wide range of creative disciplines including visual arts and film. Her recent works have been presented at some of the most prestigious art institutions in the UK and Europe, including, Lenbachhaus (Munich), Arnolfini (Bristol), Turner Contemporary (Margate), the ICA, The Roundhouse and Whitechapel Gallery (London) and Glasgow Museum of Modern Art.

Simon Ellis is an independent choreographer, dancer, film-maker and teacher. He trained at the Victorian College of the Arts in Melbourne, and is now a Reader at Roehampton Dance in London. He co-edits the International Journal of Screendance with Harmony Bench. www.skellis.net

\section{Notes}

${ }^{1}$ All This Can Happen, dir. Siobhan Davies and David Hinton, London: Siobhan Davies Dance Company, 2013, film. http://www.siobhandavies.com/work/all-this-can-happen

${ }^{2}$ The room is small. There are two tables in it, a couch, and pieces of technology and books lying around.

${ }^{3}$ The working title for The Running Tongue was The Sprint.

${ }^{4}$ Mineke Schipper, Never Marry a Woman with Big Feet: Women in Proverbs from around the World, New Haven: Yale University Press, 2004.

${ }^{5}$ Efrosini Protopapa is another London-based artist who has made visions for The Running Tongue.

${ }^{6}$ Frank Bock is also another artist involved in The Running Tongue. http://www.artsadmin.co.uk/artists/frank-bock

${ }^{7}$ Helka Kaski plays the central character in The Running Tongue who runs into each vision. http://www.siobhandavies.com/people/detail/helka-kaski/ 